\title{
Roles of Interleukin-6 and Parathyroid Hormone-Related Peptide in Osteoclast Formation Associated with Oral Cancers
}

\section{Significance of Interleukin-6 Synthesized by Stromal Cells in Response to Cancer Cells}

Kou Kayamori, ${ }^{\dagger}{ }^{\dagger}$ Kei Sakamoto, ${ }^{*}$

Tomoki Nakashima, ${ }^{\ddagger}$ Hiroshi Takayanagi, ${ }^{\dagger \ddagger}$ Kei-ichi Morita, ${ }^{\S}$ Ken Omura, ${ }^{\dagger \S}$ Su Tien Nguyen, ${ }^{\pi}$ Yoshio Miki, ${ }^{+\pi \| l \mid}$ Tadahiro limura, ${ }^{* \dagger}$ Akiko Himeno, ${ }^{* \dagger * *}$ Takumi Akashi, ${ }^{\dagger \dagger}$

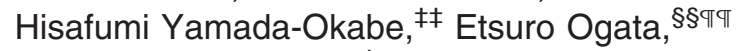
and Akira Yamaguchi ${ }^{\star \dagger}$

\footnotetext{
From the Sections of Oral Pathology, ${ }^{*}$ Cell Signaling, ${ }^{*}$ Oral and Maxillofacial Surgery, ${ }^{\S}$ and Periodontology,** Graduate School of Tokyo Medical and Dental University, Tokyo, the Global Center of Excellence Program, ${ }^{\dagger}$ International Research Center for Molecular Science in Tooth and Bone Diseases, and the Departments of Molecular Genetics, ${ }^{\pi}$ Medical Research Institute, and Pathology, ,+ Tokyo Medical and Dental University Medical Hospital, Tokyo, the Department of Genetic Diagnosis," Cancer Institute, Japanese Foundation for Cancer Research, Tokyo,

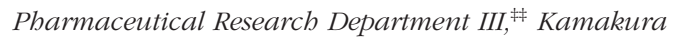
Laboratories, Chugai Pharmaceutical Co., Ltd, Kanagawa; Chugai Pharmaceutical Co., Ltd., ${ }^{\$ S}$ Tokyo, and Cancer Institute

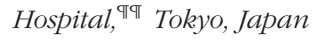

We investigated the roles of interleukin-6 (IL-6) and parathyroid hormone-related peptide (PTHrP) in oral squamous cell carcinoma (OSCC)-induced osteoclast formation. Microarray analyses performed on 43 human OSCC specimens revealed that many of the specimens overexpressed PTHrP mRNA, but a few overexpressed $I L-6$ mRNA. Immunohistochemical analysis revealed that IL-6 was expressed not only in cancer cells but also in fibroblasts and osteoclasts at the tumor-bone interface. Many of the IL-6-positive cells coexpressed vimentin. Conditioned medium (CM) derived from the culture of oral cancer cell lines (BHY, Ca9-22, HSC3, and HO1-u-1) stimulated Rankl expression in stromal cells and osteoclast formation. Antibodies against both hu- man PTHrP and mouse IL-6 receptor suppressed Rankl in ST2 cells and osteoclast formation induced by CM from BHY and Ca9-22, although the inhibitory effects of IL6 antibody were greater than those of PTHrP antibody. CM derived from all of the OSCC cell lines effectively induced IL- 6 expression in stromal cells, and the induction was partially blocked by anti-PTHrP antibody. Xenografts of HSC 3 cells onto the periosteal region of the parietal bone in athymic mice presented histology and expression profiles of RANKL and IL-6 similar to those observed in bone-invasive human OSCC specimens. These results indicate that OSCC provides a suitable microenvironment for osteoclast formation not only by producing IL-6 and PTHrP but also by stimulating stromal cells to synthesize IL-6. (Am J Pathol 2010, 176:968-980; DOI: 10.2353/ajpath.2010.090299)

Bone invasion by various malignant tumors causes diverse complications in patients. In the case of oral cancers, such invasion leads to physical damage of the bone and has a critical influence on patient prognosis. Several research groups have histopathologically investigated the process of bone destruction by oral squamous cell

Supported by a Grant-in-Aid for Scientific Research from the Japan Society for the Promotion of Science (14104015 to A.Y.) and by a grant from the Japanese Ministry of Education, Global Center of Excellence Program, "International Research Center for Molecular Science in Tooth and Bone Diseases."

Accepted for publication October 15, 2009.

Supplemental material for this article can be found on http://ajp. amjpathol.org.

Address reprint requests to Akira Yamaguchi, D.D.S., Ph.D., Section of Oral Pathology, Graduate School of Tokyo Medical and Dental University, 1-5-45 Yushima, Bunkyo-ku, Tokyo 113-8549, Japan. E-mail: akira.mpa@tmd.ac.jp. 
carcinoma (OSCC), ${ }^{1-4}$ the dominant cancer occurring in the oral cavity. Although these studies indicated that the bone destruction is mediated by osteoclasts rather than directly by cancer cells, the precise mechanism that regulates bone destruction due to OSCC has not been elucidated.

Osteoclastogenesis is regulated by a complex signaling system that involves three essential molecules of the tumor necrosis factor family, namely the receptor activator of nuclear factor- $\kappa \mathrm{B}$ (RANK), the RANK ligand (RANKL), and osteoprotegerin. ${ }^{5,6}$ RANKL is expressed in osteoblasts and bone marrow stromal cells. ${ }^{7}$ It critically regulates the differentiation and function of osteoclasts by binding to its receptor RANK, ${ }^{8,9}$ which is expressed in osteoclast lineage cells. Furthermore, osteoblasts and stromal cells synthesize osteoprotegerin, ${ }^{10}$ which is a decoy receptor for RANKL. Thus, a balance between the expression levels of RANKL and osteoprotegerin is crucial for regulating osteoclast differentiation and function.

To explore the factors that contribute to cancer-associated bone resorption, several research groups have investigated the expression of bone-resorbing factors such as interleukin (IL)- $1 \beta$, IL-6, tumor necrosis factor- $\alpha$, and parathyroid hormone-related peptide (PTHrP) in human OSCC. ${ }^{1-14}$ Among these, IL-6 is an important cytokine that stimulates osteoclastic bone resorption by inducing RANKL expression in osteoblastic cells. ${ }^{15}$ More importantly, several reports have revealed that the serum levels of IL-6 are elevated in patients with head and neck squamous cell carcinoma (SCC). ${ }^{16-18}$ Duffy et al ${ }^{18}$ reported that elevated serum IL-6 levels could serve as a valuable biomarker for predicting tumor recurrence and survival among patients with head and neck SCC. Although the increased serum IL-6 is considered to be synthesized by OSCC, this has not been well elucidated. PTHrP, which was originally identified as a factor responsible for humoral hypercalcemia of malignancy, ${ }^{19}$ is synthesized by many malignant tumors such as those in breast, lung, colon, and prostate gland. ${ }^{20-23}$ PTHrP expression in OSCCs also has been investigated. $.^{24-27} \mathrm{Be}-$ cause PTHrP stimulates osteoclast activity by inducing RANKL in osteoblastic cells, ${ }^{28}$ it might play a key role in cancer-associated bone resorption. Although previous reports have suggested the importance of IL-6 and PTHrP in OSCC-induced bone resorption, few studies have investigated extensively the roles in osteoclast formation associated with OSCC.

Cancer stroma comprises various types of cells including fibroblasts, myofibroblasts, endothelial cells, and inflammatory cells. These cells and their products play crucial roles in establishing the tumor microenvironment, which regulates the proliferation, survival, invasion, and metastasis of the cancer cells. ${ }^{29,30}$ We investigated histopathologically 97 cases of OSCCs with bone invasion and demonstrated the significant role of fibrous stroma in bone invasion. ${ }^{31}$ In all of the cases, we found that the fibrous stroma intervened between the invading cancer nests and the resorbing bone surface, and fibroblastic cells expressing RANKL were observed at the bone resorbing region close to the cancer nests, suggesting that OSCCs synthesize factor(s) that induce RANKL ex- pression in the fibrous stroma adjacent to the bone surface, leading to osteoclastic bone resorption.

In the present study, we examined the expression profiles of IL-6 and PTHrP in human OSCCs extensively and investigated the roles of IL-6 and PTHrP in osteoclast formation using various cancer cell lines. Herein we demonstrate that OSCC provides a suitable microenvironment for bone resorption not only by releasing PTHrP and IL-6 but also by stimulating stromal cells to synthesize IL-6.

\section{Materials and Methods}

\section{Antibodies Used}

Rat anti-mouse IL-6 receptor neutralizing monoclonal antibody (MR16-1) ${ }^{32}$ and mouse anti-human PTHrP neutralizing monoclonal antibody ${ }^{33}$ were provided by Chugai Pharmaceutical Co. Ltd. (Tokyo, Japan). Mouse anti-human IL-6, rat anti-mouse IL-6 neutralizing monoclonal antibodies, and rat and mouse $\operatorname{lgG}_{1}$ used as controls were purchased from R\&D Systems (Minneapolis, MN). Mouse anti-human RANKL monoclonal antibody (Calbiochem, Darmstadt, Germany), goat anti-human, mouse, and rat RANKL polyclonal antibody (sc-7628, Santa Cruz Biotechnology, Inc., Santa Cruz, CA), mouse anti-human IL-6 monoclonal antibody (Novocastra, Newcastle, UK), goat anti-mouse and rat IL-6 polyclonal antibody (sc1265; Santa Cruz Biotechnology, Inc.), rabbit anti-human vimentin monoclonal antibody (Epitomics, Burlingame, $\mathrm{CA}$ ), and rabbit anti-human CD14 and CD20 monoclonal antibodies (Epitomics) were used for immunohistochemical analyses.

\section{Laser Capture Microdissection and Microarray Analysis}

Primary oral cancer specimens were obtained from 43 anonymous patients who had been treated at the Dental Hospital of Tokyo Medical and Dental University. All cancers were histopathologically diagnosed as OSCC. None of the patients had received chemo- or radiotherapy before the specimens had been obtained. Informed consent was obtained from all of patients, and all of the experimental procedures were approved by the university ethics committee. Cancer cells were isolated from all of the hematoxylin-stained sections by laser capture microdissection as described previously. ${ }^{34}$ From 9 patients, oral epithelial tissue adjacent to the tumor was also isolated by laser capture microdissection to compare the expression levels in this tissue with those in cancer cells. Microarray analyses were conducted on the samples using the Human Genome U24133 Plus 2.0 array purchased from Affymetrix as described previously. ${ }^{34}$ Of the 43 cases of OSCCs in this study, 30 had been analyzed by microarrays in our previous report. ${ }^{34}$ The expression level of mRNA was determined by fluorescence intensity, which was the absolute value of fluorescence intensity in each case. 


\section{Histochemical and Immunohistochemical Staining}

After fixation in $10 \%$ neutral buffered formalin, small blocks approximately $1.5 \times 1.0 \times 0.5 \mathrm{~cm}$ containing the interface of tumor and bone were dissected from 13 of the surgical cases. These specimens were decalcified in $10 \%$ EDTA at $4^{\circ} \mathrm{C}$ for 4 weeks and embedded in paraffin. For immunohistochemical staining, the sections were pretreated with microwave irradiation in $0.01 \mathrm{~mol} / \mathrm{L}$ citric acid for 1 hour at $80^{\circ} \mathrm{C}$ for RANKL antibody or PBS containing $0.1 \mathrm{mg} / \mathrm{ml}$ trypsin (BD, Franklin Lakes, $\mathrm{NJ}$ ) for 30 minutes at $37^{\circ} \mathrm{C}$ for IL-6 antibody. After quenching of endogenous peroxidase activity by incubation in $0.3 \%$ hydrogen peroxide solution for 20 minutes, the sections were incubated overnight at $4^{\circ} \mathrm{C}$ with mouse anti-human RANKL monoclonal antibody (1:50) or mouse anti-human IL-6 antibody (1:50). After washing with PBS, the sections were incubated with peroxidase-conjugated secondary antibody (EnVision + Dual Link System Peroxidase Kit, DakoDenmarkA/S, Glostrup, Denmark) for 1 hour. Diaminobenzidine was used as a chromogen. The RANKL- and IL-6-positive fibroblastic cells present between the invading tumor nests and the bone resorption surface were counted using Scion Imaging Software.

For immunofluorescent antibody staining, the specimens were dual-stained with a mouse anti-human IL-6 antibody (1:50) and goat anti-human vimentin antibody (1:200), anti-human CD14 antibody (1:500), or CD20 antibody (1:100) as a primary antibody. Goat anti-mouse IgG Alexa Fluor 488 and goat anti-rabbit IgG Alexa Fluor 594 (Invitrogen, Carlsbad, CA) were used as secondary antibodies and sections were incubated overnight at $4^{\circ} \mathrm{C}$. After immunofluorescent antibody staining, specimens were scanned by a confocal laser microscope (Pascal LSM5, Carl Zeiss GmbH, Jena, Germany) with excitation wave lengths of 488 and $543 \mathrm{~nm}$. Acquired fluorescent images and differential interference contrast images were processed using LSM Image browser (Carl Zeiss GmbH).

For immunohistochemical staining in the xenograft experiments, we used goat anti-human, mouse, and rat RANKL polyclonal antibody (Santa Cruz Biotechnology, Inc.), goat anti-mouse and rat IL-6 polyclonal antibody (Santa Cruz Biotechnology, Inc.), and mouse anti-human IL-6 monoclonal antibody (Novocastra) as primary antibodies. As secondary antibodies, an Imm PRESS REAGENT KIT with anti-goat Ig (MP-7405, Vector Laboratories, Burlingame, CA) was used to detect immunoreaction with goat antibodies and a Histofine Mouse Stain Kit (414322, Nichirei Corporation, Tokyo, Japan) was applied to detect immunoreaction with mouse antibody.

\section{Cell Culture}

We used four human OSCC cell lines (BHY, Ca9-22 [Ca9], HSC3, and HO1-u-1 [HO1]). BHY and Ca9 are derived from human gingival SCC, HSC3 from SCC of tongue, and $\mathrm{HO} 1$ from SCC of the floor of the mouth. In addition, we used four cancer cell lines derived from nonoral regions (EBC1, MKN28, A549, and MCF7). EBC1 is derived from lung SCC, MKN28 from gastric adenocarcinoma, A549 from lung adenocarcinoma, and MCF7 from breast adenocarcinoma. All cell lines were maintained in Dulbecco's modified Eagle's medium containing 10\% fetal bovine serum (FBS) (Sigma-Aldrich, St. Louis, MO), 50 units $/ \mathrm{ml}$ penicillin $\mathrm{G}$, and $50 \mathrm{mg} / \mathrm{ml}$ streptomycin. The stromal cell line ST2, derived from mouse bone marrow, was maintained in RPMI 1640 medium containing 10\% FBS. Human bone marrow-derived mesenchymal stem cells were cultured in Dulbecco's modified Eagle's medium containing 10\% FBS, 2 ng/ml basic fibroblast growth factor, and antibiotics. ${ }^{35} \mathrm{BHY}$ was provided by Dr. Masato Okamoto (TELLA Inc., Tokyo, Japan), and Ca9-22 and HSC3 were purchased from the Japanese Collection of Research Bioresources. HO1-u-1 and MCF7 were provided by the Cell Resource Center for Biomedical Research (Tohuku University, Miyagi, Japan). EBC1, MKN28, A549, ST2, and human mesenchymal stem cells were purchased from RIKEN BioResource Center (Tsukuba, Japan).

\section{Preparation of Conditioned Medium from Cancer Cell Lines}

All of the cancer cells were grown to confluence in $100-\mathrm{mm}$ dishes in Dulbecco's modified Eagle's medium containing 10\% FBS. After washing with PBS three times, they were cultured for an additional 48 hours in $4 \mathrm{ml}$ of serum-free $\alpha$-modified minimum essential medium. The collected culture supernatants were centrifuged at 1500 rpm for 5 minutes and filtered using a $0.22-\mu \mathrm{m}$ filter unit. The media thus obtained were stored at $-80^{\circ} \mathrm{C}$ and used as conditioned medium (CM). For all experiments, the $\mathrm{CM}$ was diluted with $\alpha$-modified minimum essential medium in a $1: 1$ ratio (50\%).

\section{RT-PCR Analyses}

Total RNA extracted from the cultured cells was reversetranscribed into cDNA using a First-Strand cDNA Synthesis Kit for RT-PCR (Roche Diagnostics, Indianapolis, IN). The cDNA products were amplified by RT-PCR using gene-specific primers as shown in Table 1. The amplified products of human PTHrP, human $I L-6$, human OPG, and human $A C T B$ were electrophoresed on $2 \%$ agarose gel and visualized under UV light illumination after staining ethidium bromide staining. The mRNA expression levels of human RANKL, mouse Rankl, mouse Opg, human IL-6, and mouse II- 6 were quantified by real-time RT-PCR using a Light-Cycler System (Roche Diagnostics) and a Platinum SYBR Green qPCR SuperMix UDG kit (Invitrogen) with the specific primers as shown in Table 1. The relative expression level of each mRNA was normalized to the 18S rRNA expression level.

\section{Osteoclast Formation}

The osteoclast formation activity in the CM was assessed using an in vitro osteoclast formation assay. ${ }^{36}$ We inocu- 
Table 1. Primers Sequences Used for RT-PCR

\begin{tabular}{|c|c|c|}
\hline Gene & Forward primer & Reverse primer \\
\hline Human PTHrP & 5'-GCTGTGTCTGAACATCAGCT-3' & $3^{\prime}$-TTTGTACGTCTCCACCTTG-5' \\
\hline Human RANKL & $5^{\prime}$-CCAGCATCAAAATCCCAAGT-3' & $3^{\prime}$-CCCCAAAGTATGTTGCATCCTG-5' \\
\hline Human IL-6 & 5'-AAATTCGGTACATCCTCGAC-3' & $3^{\prime}$-CAGGAACTGGATCAGGACTT-5' \\
\hline Human ACTB & $5^{\prime}-$ AAACTGGAACGGTGAAGGTG-3' & $3^{\prime}-$ TCAAGTTGGGGGACAAAAAG- $5^{\prime}$ \\
\hline Mouse Pthrp & 5'-CGGTTTGGGTCAGACGATG-3' & 3'-TTCCCGGTGTCTTGAGTG-5' \\
\hline Mouse Rankl & 5'-ATGATGGAAGGCTCATGGT-3' & $3^{\prime}$-CCAAGAGGACAGAGTGACTTT-5' \\
\hline Mouse Opg & 5'-CTGCCTGGGAAGAAGATCAG-3' & $3^{\prime}-$ TTGTGAAGCTGTGCAGGAAC-5' \\
\hline Mouse II-6 & $5^{\prime}$-GAGGATACCACTCCCAACAGACC-3' & $3^{\prime}$-AAGTGCATCATCGTTGTTCATACA-5' \\
\hline Mouse Tnf- $\alpha$ & 5'-GGCATGGATCTCAAAGACAACC-3' & $3^{\prime}$-CAGGTATATGGGCTCATACCAG-5' \\
\hline 18SrRNA & 5'-GTAACCCGTTGAACCCCATT-3' & $3^{\prime}$-CCATCCAATCGGTAGTAGCG-5' \\
\hline
\end{tabular}

lated ST2 cells onto a 24-well plate $\left(5 \times 10^{4}\right.$ cells/well $)$ and cultured them in $\alpha$-modified minimum essential medium containing $10 \%$ FBS, $1 \times 10^{-8} \mathrm{~mol} / \mathrm{L} \mathrm{1,25-dehy-}$ droxyvitamin $D_{3}$ (Sigma-Aldrich), and $1 \times 10^{-7} \mathrm{~mol} / \mathrm{L}$ dexamethasone (Sigma-Aldrich) for 24 hours. Then, mouse bone marrow cells $\left(5 \times 10^{5}\right.$ cells/well) isolated from the femora and tibiae of 6 -week-old C57BL/6 mice were cocultured with ST2 cells in $0.5 \mathrm{ml}$ of $\alpha$-modified minimum essential medium containing 10\% FBS, $1 \times$ $10^{[8} \mathrm{mol} / \mathrm{L} 1,25$-dehydroxyvitamin $\mathrm{D}_{3}$, and $1 \times 10^{-7} \mathrm{~mol} / \mathrm{L}$ dexamethasone in the presence or absence of $\mathrm{CM}$ derived from each cancer cell line. The culture medium was replaced every other day. After coculturing for 6 days, the cells were fixed in $10 \%$ buffered formalin and stained with tartrate-resistant acid phosphatase for osteoclast identification by incubation with $0.1 \mathrm{~mol} / \mathrm{L}$ sodium acetate buffer ( $\mathrm{pH}$ 5.0) containing AS-MX phosphate (SigmaAldrich) and red violet LB salt (Sigma-Aldrich) in the presence of $50 \mathrm{mmol} / \mathrm{L}$ sodium tartrate (Sigma-Aldrich). Tartrate-resistant acid phosphatase-positive cells that contained more than three nuclei were identified as osteoclasts and were counted.

\section{Xenograft Experiments of HSC3 Cells into Athymic Mice}

HSC3 cells $\left(5 \times 10^{5}\right.$ cells/injection) were injected onto the periosteal region of the parietal bones in athymic mice using a 1-ml syringe after the periosteum was scratched once with the syringe needle. Three weeks after the transplantation, the calvarial region was dissected and fixed with 4\% paraformaldehyde. Soft X-ray photographs were taken after fixation. The tissues were embedded in paraffin after decalcification with $10 \%$ EDTA at $4^{\circ} \mathrm{C}$ for 10 days. The sections were used for histological observation including immunohistochemical analysis for RANKL, human IL-6, and mouse IL-6. The experimental procedures were reviewed and approved by the Animal Care and Use Committees at Tokyo Medical and Dental University.

\section{Statistical Analyses}

Statistical analyses were performed using Student's $t$-test and Pearson's correlation coefficient. $P<0.05$ was considered significant. The data are the mean \pm SEM of independent replicates.

\section{Results}

\section{Expression of IL-6 and PTHrP mRNA in Primary Human OSCC}

The clinical and pathological data for the 43 cases of primary OSCC used for microarray analysis are summarized in Table 2. As shown in Figure 1A, mRNA expression of $I L-6$ varied among the cancers and the oral epithelium adjacent to the cancers. Although only two SCC specimens expressed IL-6 mRNA at extremely high levels, the average fluorescence intensity in the cancer cells was $199.82 \pm 427.67$ and that in the adjacent oral epithelium was $302.92 \pm 367.88$ without a significant difference between these two groups (Figure 1A). In contrast, most of the cancer tissue specimens overexpressed PTHrP mRNA (average fluorescence intensity $735.58 \pm$ 769.59) compared with the adjacent epithelial specimens (average fluorescence intensity $20.59 \pm 12.80$ ) (Figure 1B), demonstrating significantly higher expression level of PTHrP mRNA in the cancer tissues than in the adjacent epithelium $(P<0.000001)$. These results imply that many of the OSCC specimens overexpressed PTHrP mRNA, but few overexpressed IL-6 mRNA, compared with the adjacent epithelium specimens.

\section{Expression of IL-6 at Bone Invasive Region in Gingival SCC}

To confirm the expression profile of IL-6 by microarray analysis, we examined immunohistochemically the distribution of IL-6-positive cells at the bone-invasive regions in gingival SCC. Although IL-6 was expressed in some tumor cells and oral epithelia adjacent to the tumors, expression varied among the cases studied. More importantly, the fibroblastic cells at the tumor-bone interface also expressed IL-6 (Figure 2, A and B). Incubation of the sections with nonimmunized IgG exhibited no positive reactions (data not shown). The fibroblastic cells at the bone-invasion region also expressed RANKL (Figure $2 \mathrm{C}$ ). These findings were noted in 10 of 13 specimens examined; we further analyzed the distribution of the positive cells in these 10 specimens by histomorphometry. Because the percentages of RANKL- and IL-6-positive cells among the total number of fibroblasts in a given area varied among the specimens examined (RANKL-positive cells, 11.4 to $65.9 \%$; IL-6-positive cells, 25.1 to $84.1 \%$ ), 
Table 2. Clinical and Histological Characteristics of the 43 Cases of Primary Human Oral Squamous Cell Carcinoma Used for Microarray Analysis

\begin{tabular}{|c|c|c|c|c|c|c|}
\hline Case & Sex & Age & Primary site & $\mathrm{T}$ & $N$ & Histological grade* \\
\hline 1 & $M$ & 56 & Lower gingiva & 2 & 0 & Moderately \\
\hline 2 & M & 55 & Upper gingiva & 2 & 0 & Well \\
\hline 3 & M & 56 & Upper gingiva & 2 & 0 & Well \\
\hline 4 & $\mathrm{~F}$ & 64 & Lower gingiva & $4 a$ & 1 & Well \\
\hline 5 & $M$ & 77 & Lower gingiva & 2 & $2 b$ & Poorly \\
\hline 6 & M & 78 & Lower gingiva & 2 & 1 & Well \\
\hline 7 & M & 71 & Lower gingiva & 3 & $2 b$ & Well \\
\hline 8 & M & 60 & Lower gingiva & 4 & $2 b$ & Moderately \\
\hline 9 & $M$ & 57 & Upper gingiva & $4 a$ & 1 & Poorly \\
\hline 10 & M & 52 & Lower gingiva & $4 a$ & $2 b$ & Moderately \\
\hline 11 & M & 66 & Lower gingiva & 2 & 0 & Well \\
\hline 12 & $\mathrm{~F}$ & 66 & Upper gingiva & 2 & 0 & Moderately \\
\hline 13 & M & 72 & Lower gingiva & 2 & 0 & Well \\
\hline 14 & M & 68 & Lower gingiva & $4 a$ & $2 b$ & Moderately \\
\hline 15 & $\mathrm{~F}$ & 66 & Tongue & 2 & 0 & Moderately \\
\hline 16 & M & 80 & Tongue & 2 & 0 & Well \\
\hline 17 & M & 30 & Tongue & 2 & 0 & Well \\
\hline 18 & $\mathrm{~F}$ & 60 & Tongue & 2 & 0 & Well \\
\hline 19 & $M$ & 59 & Tongue & 3 & 0 & Moderately \\
\hline 20 & M & 54 & Tongue & 1 & 0 & Well \\
\hline 21 & M & 43 & Tongue & 2 & 0 & Moderately \\
\hline 22 & M & 46 & Tongue & 2 & 0 & Well \\
\hline 23 & M & 58 & Tongue & 2 & 0 & Well \\
\hline 24 & M & 66 & Tongue & 1 & $2 b$ & Moderately \\
\hline 25 & M & 61 & Tongue & 1 & $2 c$ & Moderately \\
\hline 26 & $M$ & 70 & Tongue & 3 & 1 & Moderately \\
\hline 27 & M & 37 & Tongue & 2 & 3 & Poorly \\
\hline 28 & M & 73 & Tongue & 2 & 0 & Poorly \\
\hline 29 & M & 32 & Tongue & 3 & 0 & Moderately \\
\hline 30 & $\mathrm{~F}$ & 54 & Tongue & 2 & $2 b$ & Moderately \\
\hline 31 & M & 60 & Tongue & 4 & $2 c$ & Moderately \\
\hline 32 & M & 53 & Tongue & 2 & $2 b$ & Moderately \\
\hline 33 & M & 62 & Buccal mucosa & 1 & 0 & Well \\
\hline 34 & $\mathrm{~F}$ & 74 & Buccal mucosa & 2 & 1 & Moderately \\
\hline 35 & M & 71 & Buccal mucosa & 3 & $2 b$ & Poorly \\
\hline 36 & M & 58 & Floor of mouth & 2 & 0 & Well \\
\hline 37 & M & 58 & Floor of mouth & 3 & 0 & Moderately \\
\hline 38 & M & 66 & Floor of mouth & 3 & 1 & Moderately \\
\hline 39 & M & 59 & Floor of mouth & 4 & 1 & Moderately \\
\hline 40 & M & 67 & Floor of mouth & 4 & 1 & Well \\
\hline 41 & M & 72 & Hard palate & 1 & 0 & Moderately \\
\hline 42 & $\mathrm{~F}$ & 81 & Retromolar pad & 1 & 0 & Well \\
\hline 43 & M & 68 & Retromolar pad & 2 & 0 & Moderately \\
\hline
\end{tabular}

M, male; F, female; T, tumor; N, node.

*Histological grading: well, well differentiated SCC; moderately, moderately differentiated SCC; poorly, poorly differentiated SCC.

we tested the correlation between the numbers of each cell type per specimen. The number of RANKL-positive fibroblastic cells correlated significantly with the IL-6positive fibroblastic cells at the tumor-bone interface $(r=$ 0.935926, $Y=0.8115 X-28.644, P<0.0001$ ) (Figure 2D), suggesting that the RANKL and IL- 6 synthesized by stromal cells interact closely. The RANKL-positive cells are located close to the bone surface and osteoclasts (Figure 2C). The distribution of IL-6-positive cells at the tumor-bone interface varied depending on the areas examined in each case; the cells were located close to the cancer nests at some areas (Figure 2B) and to the bone and osteoclasts at other areas (Figure 3, B-D).

To further characterize the IL-6-positive cells, we performed dual immunohistochemical analysis using fluorescence-labeled antibodies. Numerous fibroblastic cells expressed IL-6; furthermore, IL-6 expression was also observed in cancer cells located at the periphery of cancer nests (Figure 3, B-D). Several osteoclasts were also IL-6-positive (arrows in Figure 3, A and C). Many IL-6-positive fibroblastic cells coexpressed vimentin (Figure $3 \mathrm{~B}$ ); furthermore, the number of IL-6-positive fibroblastic cells was very high compared with the number of IL-6-positive B cells (Figure 3C) and macrophages (Figure 3D), suggesting that fibroblastic cells dominantly produce IL-6.

\section{Human Oral Cancer Cells Secrete Factors That Stimulate Osteoclast Formation by Inducing RANKL Expression in Stromal Cells}

We performed in vitro experiments to examine whether $\mathrm{CM}$ derived from the various cancer cell lines could induce RANKL expression in stromal cells. The CM derived from all cancer cell lines, with the exception of A549, 


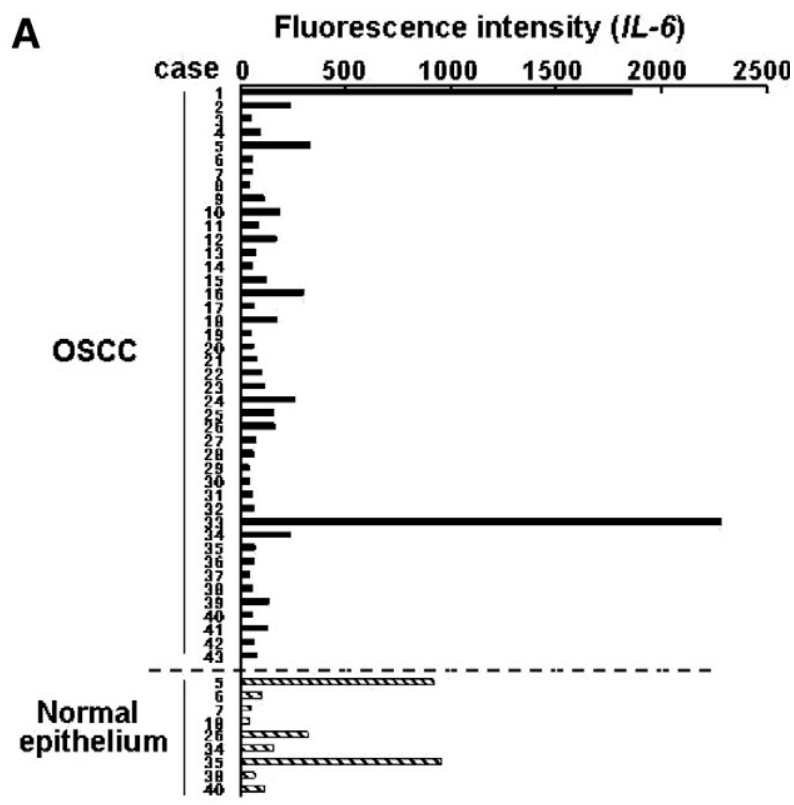

B

Fluorescence intensity (PTHrP)

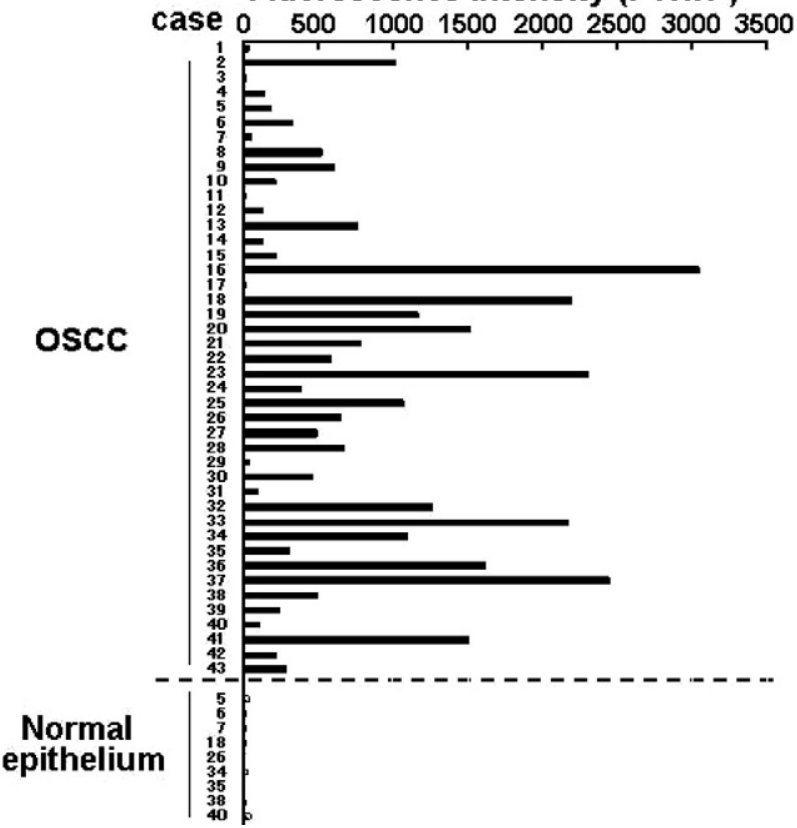

Figure 1. Expression of $I L-6$ and PTHrP in OSCC. Expression profiles of $I L-6$ (A) and PTHrP mRNA (B) in 43 primary human OSCC specimens assessed by microarray analyses as described in Materials and Methods. Expression levels in normal epithelium are also shown at the bottom of $\mathbf{A}$ and $\mathbf{B}$. The fluorescence intensity, which was the absolute value of fluorescence intensity in each case, was used to indicate the mRNA expression level.

stimulated Rankl mRNA expression in ST2 cells (Figure 4A). The CM derived from BHY and HSC3 cells markedly increased this expression. In addition, the CM derived from oral cancer cell lines (BHY, Ca9, and HSC3) significantly enhanced RANKL mRNA expression in mesenchymal stem cells isolated from human bone marrow (Figure 4B). However, none of the CM significantly altered Opg mRNA expression (data not shown).

We also investigated the effects of $\mathrm{CM}$ on osteoclast formation by using a mouse coculture system. As shown in Figure $4 \mathrm{C}$, the $\mathrm{CM}$ derived from all of the cancer cell lines increased the number of tartrate-resistant acid phosphatase-positive osteoclasts. These results suggest that oral cancer cell lines as well as cancer cells originating from nonoral regions stimulate osteoclast formation by inducing RANKL expression in stromal cells.

\section{IL-6 and PTHrP Synthesized by Cancer Cells Are Involved in RANKL Expression and Osteoclast Formation}

We then investigated the expression levels of IL-6 and $\mathrm{PTHrP}$ in various cancer cell lines. As shown in Figure 5A, all of the cell lines expressed PTHrP mRNA at substantial levels, whereas only BHY and HSC3 cells, which are derived from OSCC, expressed IL-6 mRNA at substantial levels. These results suggest that many OSCC cells express PTHrP, but only limited numbers of OSCC express $I L-6$.

To explore the roles of IL-6 and PTHrP, we next examined the effects of neutralizing antibodies against mouse IL-6 receptor ${ }^{32}$ and human PTHrP $^{33}$ on Rankl mRNA expression in ST2 cells. Both antibodies inhibited BHY-CMinduced Rankl mRNA expression (Figure 5B) in a dosedependent manner (Supplemental Figure S1, see http:// ajp.amjpathol.org). The maximum concentration of PTHrP antibody used $(10 \mu \mathrm{g} / \mathrm{ml})$ almost completely blocked PTHrP-induced CAMP production in ROS 17/2.8-5 cells. ${ }^{33}$ Similar results were obtained with HSC3-CM (data not shown). Because BHY and HSC3 cells expressed IL-6 mRNA at substantial levels, we tested the effects of these antibodies on Rankl mRNA expression by using CM derived from Ca9 cells (Ca9-CM), which expresses IL-6 mRNA at undetectable levels (Figure 5A). As expected, human PTHrP antibody significantly inhibited Ca9-CMinduced Rankl expression in ST2 cells (Figure 5C). Interestingly, anti-mouse IL-6 receptor antibody inhibited RankI mRNA expression more effectively than anti-human PTHrP antibody (Figure 5C). These results suggest that IL-6 synthesized not only by human oral cancer cells but also by mouse ST2 cells can stimulate Rankl expression in ST2 cells.

As shown in Figure 5D, antibodies against both human PTHrP and mouse IL-6 receptor significantly inhibited $\mathrm{BHY}-\mathrm{CM}$-induced osteoclast formation. Considered collectively, these results suggest that IL-6 and PTHrP are involved in the osteoclast formation induced by OSCC.

\section{Oral Cancers Induce IL-6 Expression in Stromal Cells, Leading to RANKL Expression}

The results described above suggest that oral cancer cells induce IL-6 expression in stromal cells and that this cytokine in turn plays a role in osteoclast formation induced by OSCC. The distribution of IL-6-positive fibroblastic cells in human gingival SCC as determined by immunohistochemical analysis (Figures 2 and 3) strongly supports this hypothesis. To confirm this finding, we investigated the effects of the $\mathrm{CM}$ derived from all of the 

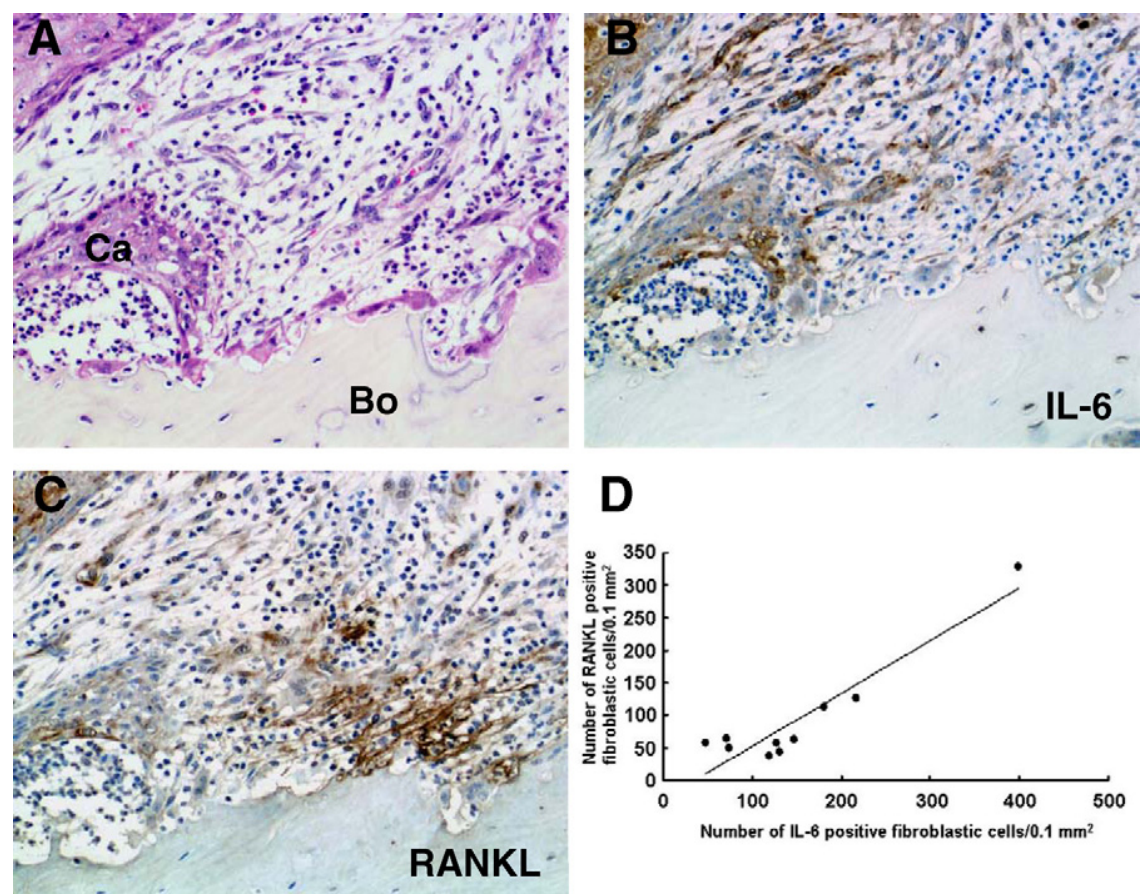

Figure 2. Distribution of RANKL-positive and IL-6-positive cells at the interface of the tumor front and resorbing bone in human gingival SCC. A: Histological analysis of tumor-bone interface. $\mathrm{Ca}$, cancer cells; Bo, bone. H\&E staining. B: Distribution of IL-6-positive cells. C: Distribution of RANKL-positive cells. Cells stained brown in $\mathbf{B}$ and $\mathbf{C}$ represent positive cells for each antibody. Original magnification, $\times 200$. D: Correlation between the number of RANKL-positive and IL-6-positive fibroblastic cells at the tumorbone interface in 10 human gingival SCCs; a positive correlation was noted $(r=0.935926$, $Y=0.8115 X-28.644, P<0.0001)$. cancer cell lines on IL-6 expression in stromal cells. We found that $\mathrm{CM}$ derived from oral cancer cell lines significantly increased II-6 mRNA expression in ST2 cells (Figure $6 \mathrm{~A}$ ). The stimulatory effects of $\mathrm{CM}$ derived from $\mathrm{BHY}$ and HSC3 cells were much higher than those of CM from
$\mathrm{Ca} 9$ and $\mathrm{HO} 1$ cells. The $\mathrm{CM}$ derived from the non-oral cancer cell lines, with the exception of MCF7, failed to induce II-6 mRNA expression (Figure 6A). The CM derived from every cancer cell line induced the production of IL-6 protein from ST2 cells in a similar fashion to levels
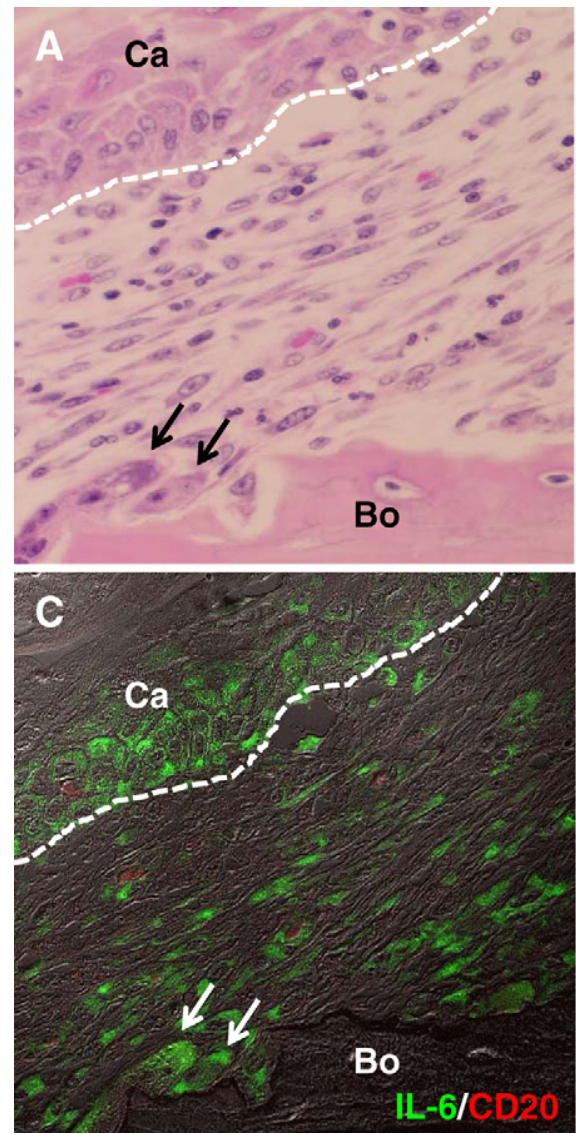
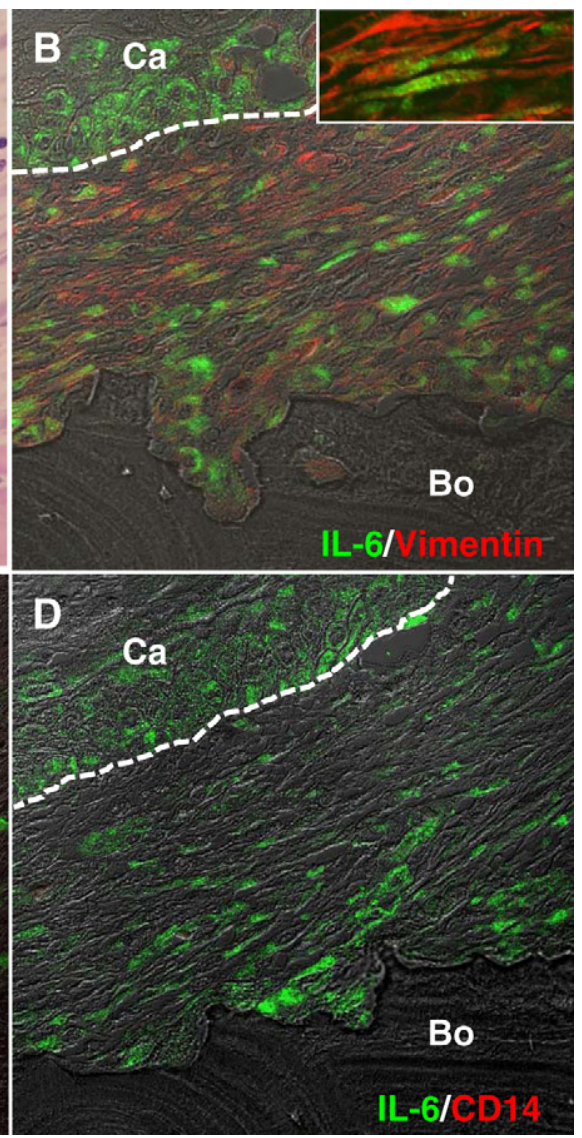

Figure 3. Characterization of IL-6-positive cells at the interface of the tumor front and resorbing bone in human gingival SCC. A: Histology of the tumor-bone interface. H\&E staining. B: Dual immunohistochemical analysis for IL-6 (green) and vimentin (red). Inset: High magnification image of the fibroblastic cells dual positive for IL- 6 and vimentin. C: Dual staining for IL-6 (green) and CD20 (red). D: Dual staining for IL-6 (green) and CD14 (red). A and $\mathbf{C}$ are the same section; the section was stained with H\&E (A) after pictures were taken for immunohistochemical analysis in (C). White dotted lines indicate interfaces of cancer nest and stroma. Arrows in $\mathbf{A}$ and $\mathbf{C}$ indicate osteoclasts. Ca, cancer cells, Bo, Bone. Original magnification: $\times 400(\mathbf{A}-\mathbf{D}) ; \times 1600$ (inset in A). 
A
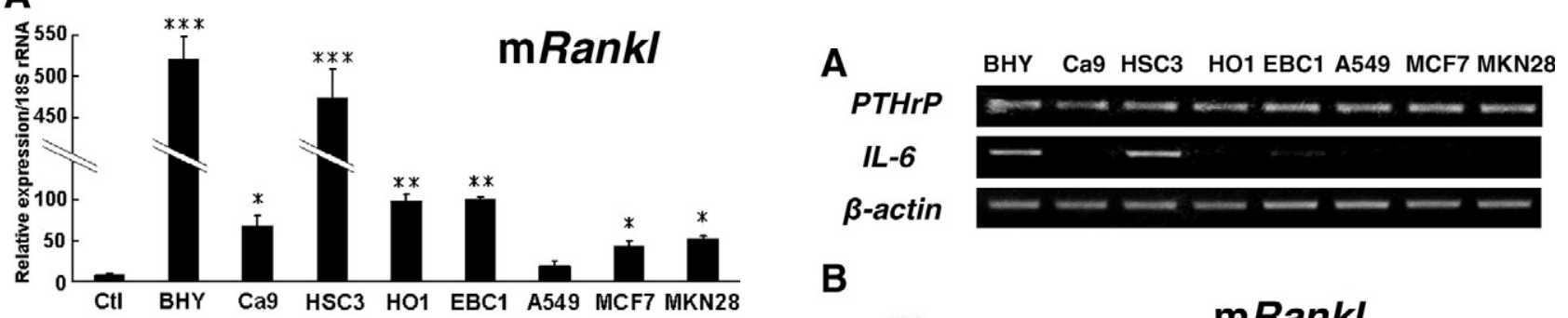

B

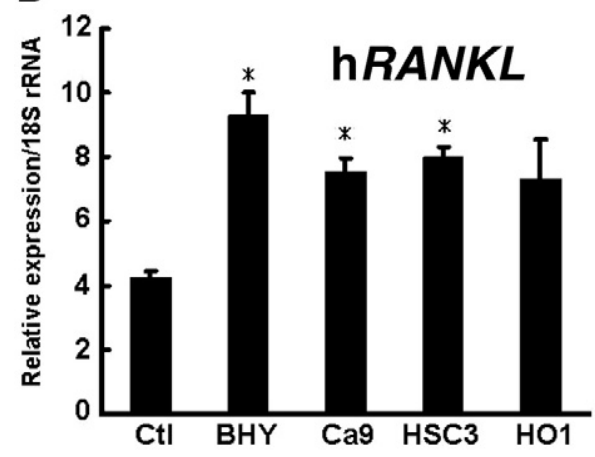

B

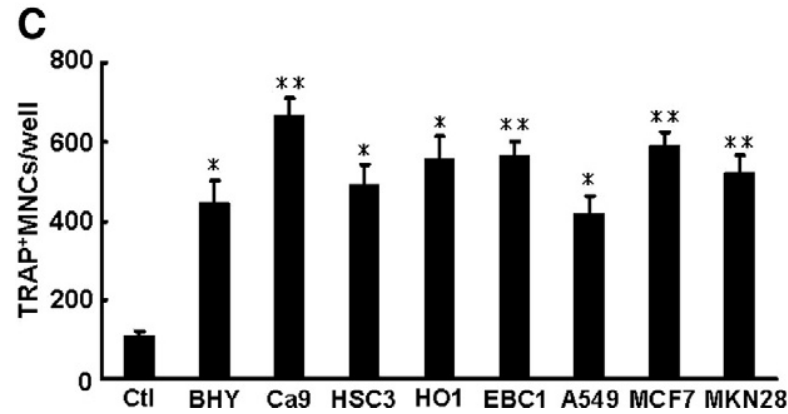

Figure 4. Effects of $\mathrm{CM}$ on RANKL expression in stromal cells and on osteoclast formation. Effects of $\mathrm{CM}$ derived from various cancer cell lines on mouse Rankl (mRankl) mRNA expression in ST2 cells (A). ST2 cells were cultured for 2 days in the presence or absence (Ctl) of CM derived from various cancer cell lines, and the expression levels of $R a n k l$ were determined by using mouse specific primers. ${ }^{*} P<0.05$, ${ }^{* * *} P<0.01$, ${ }^{* * * *} P<0.005$, significantly different from Ctl. B: Effects of CM derived from OSCC cell lines on human RANKL (hRANKL) mRNA expression in human mesenchymal stem cells. These cells were cultured for 2 days with or without (Ctl) $\mathrm{CM}$, and the expression levels of $R A N K L$ were determined by using human specific primers. ${ }^{*} P<0.01$, significantly different from Ctl. C: Effect of $\mathrm{CM}$ derived from various cancer cell lines on osteoclast formation. Osteoclast formation was assessed by adding CM from various cancer cell lines to coculture of ST2 with mouse bone marrow cells as described in Materials and Methods. ${ }^{*} P<0.01$, ${ }_{* * *} P<0.005$, significantly different from the control (Ctl). TRAP, tartrateresistant acid phosphatase; MNCs, mononuclear cells.

of II-6 mRNA induced by each CM (Figure 6B). CM derived from OSCC cell lines also enhanced IL-6 mRNA expression in human mesenchymal stem cells (Figure $6 \mathrm{C})$. These results indicate that oral cancer cells effectively induce IL-6 expression in stromal cells. None of the CM induced Pthrp or Tnf- $\alpha$ mRNA expression in ST2 cells (Supplemental Figure S2, see http://ajp.amjpathol.org).

To discriminate between the roles of IL-6 synthesized by cancer cells and stromal cells in the induction of Rankl expression, we conducted experiments using antibodies that specifically neutralize human IL-6 and mouse IL-6. Both antibodies inhibited BHY-CM-induced Rankl mRNA expression in ST2 cells (Figure 7A). Moreover, compared with treatment with one of these antibodies alone, simul-

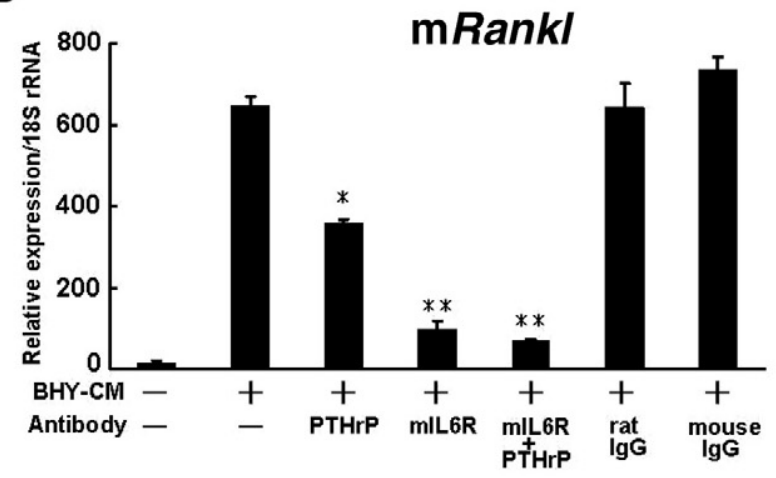

C
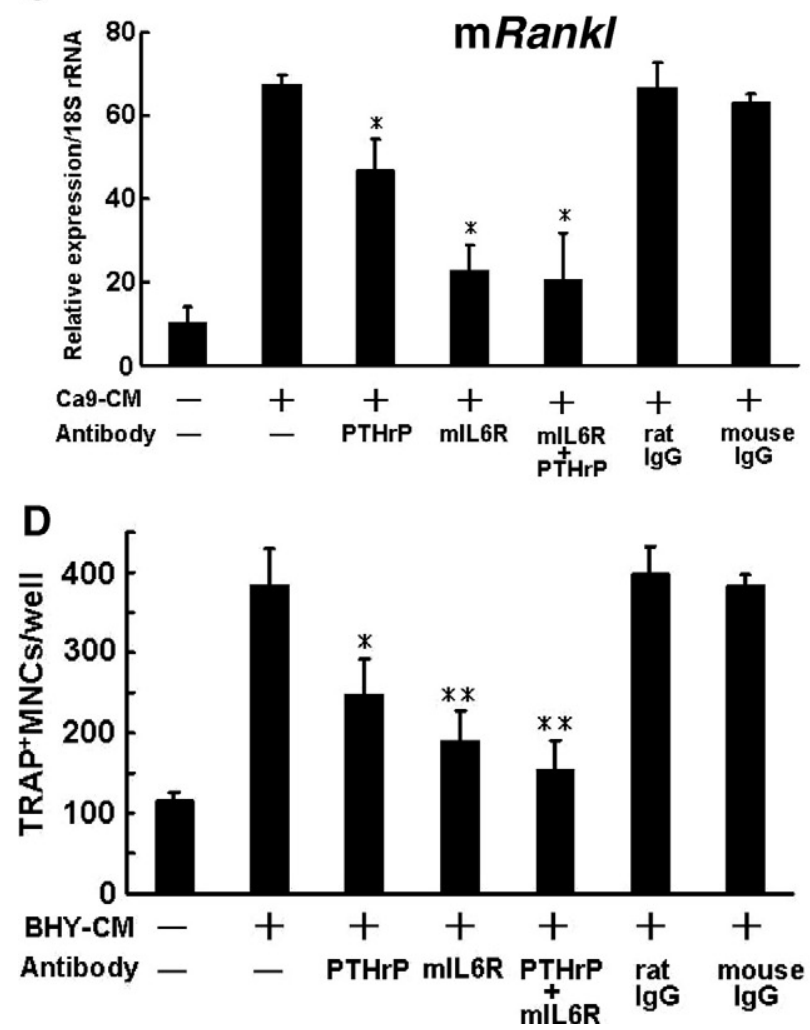

Figure 5. Role of IL-6 and PTHrP in Rankl expression and osteoclast formation. A: mRNA expression of $I L-6$ and PTHrP in various cancer cell lines. $\mathbf{B}$ and $\mathbf{C}$ : Effects of anti-human PTHrP antibody and anti-mouse IL-6 (mIL-6) receptor antibody on Rankl mRNA expression induced by BHY-CM (B) and Ca9-CM (C) in ST2 cells. ST2 cells were cultured for 2 days in the presence or absence of BHY or Ca9-CM, and the expression of Rankl was determined by using mouse specific primers. ${ }^{*} P<0.05$, ${ }^{* *} P<0.01$, significantly different from the value for $\mathrm{BHY}-\mathrm{CM}(+)$ and antibody $(-)$ in $\mathbf{B}$, and ${ }^{*} P<0.05$, significantly different from the value for $\mathrm{Ca} 9-\mathrm{CM}(+)$ and antibody $(-)$ in C. D: Effects of anti-human PTHrP and anti-mouse IL-6 receptor antibodies on formation of tartrate-resistant acid phosphatase (TRAP)-positive osteoclast after stimulation with BHY-CM in cocultured ST2 and bone marrow cells. ${ }^{*} P<0.01,{ }^{* *} P<0.005$, significantly different from the value of BHY-CM treated cells without any antibodies. In each experiment, the cells were treated with $10 \mu \mathrm{g} / \mathrm{ml}$ of each antibody. MNCs, multinucleated cells. 
A

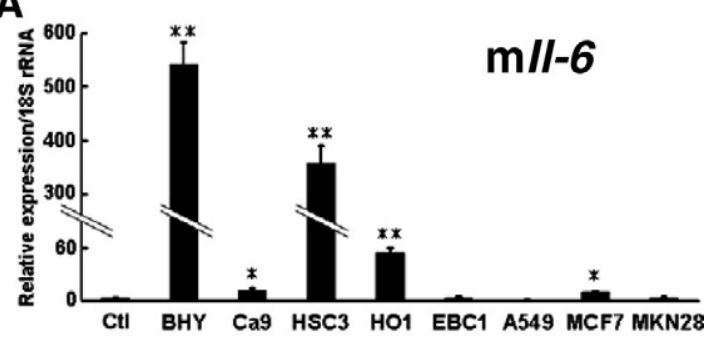

B

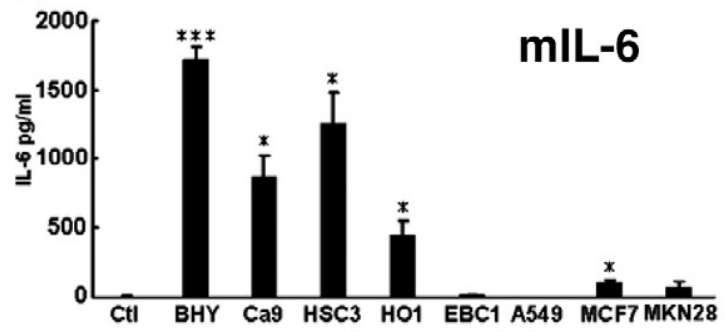

C

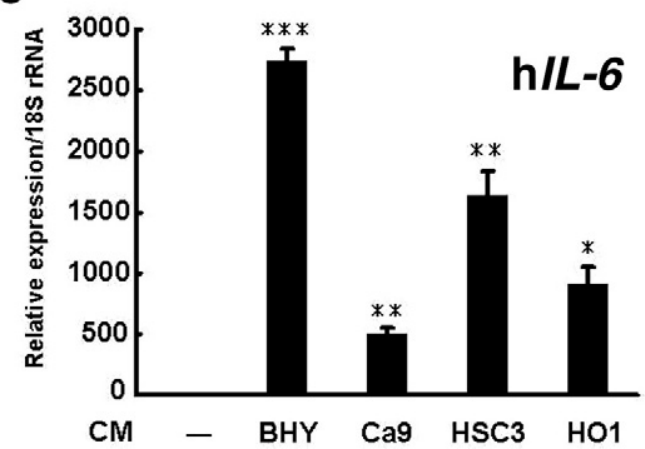

Figure 6. Stimulation of IL-6 in ST2 cells and human mesenchymal stem cells by various cancer cell lines. Effects of CM derived from various cancer cell lines on Il-6 mRNA expression (A) and IL-6 production (B) in ST2 cells. ST2 cells were cultured for 2 days in the presence or absence $(\mathrm{Ctl})$ of $\mathrm{CM}$ derived from various cancer cells and mouse $\mathrm{Il}-6$ (mIL-6) mRNA expression was determined by using mouse specific primers (A). IL-6 protein levels secreted by ST2 cells, which were measured by enzyme-linked immunosorbent assay using culture supernatants obtained from ST2 cells cultured for 24 hours with various $\mathrm{CM}$ in the absence of FBS $(\mathbf{B}) .{ }^{*} P<0.05,{ }^{* * *} P<0.005$, ${ }^{* * * *} P<0.0005$, significantly different from the control culture (Ctl). C: Effects of CM derived from OSCC cell lines on human $I L-6$ (hIL-6) mRNA expression in human mesenchymal stem cells. These cells were cultured for 2 days in the presence or absence of CM derived from OSCC cells, and the expression of human $I L-6$ mRNA was examined by using human specific primers. " $P<$ 0.001 , ${ }^{* *} P<0.005,{ }^{* * * * *} P<0.0005$, significantly different from human mesenchymal stem cells cultured in the absence of any CM.

taneous treatment with both produced an additive inhibitory effect on Rankl mRNA expression (Figure 7A). When we used CM derived from Ca9 cells (Ca9-CM), which expressed IL-6 mRNA at undetectable levels (Figure 5A), the anti-human IL-6 antibody did not alter RankI mRNA expression, whereas anti-mouse IL-6 antibody significantly inhibited it (Figure 7B). These results demonstrate that IL-6 synthesized by both cancer cells and stromal cells induces RANKL expression in stromal cells.

We explored the factors that regulate IL-6 production in stromal cells. Because PTHrP is reported to stimulate IL-6 synthesis in osteoblastic cells, ${ }^{37}$ we examined the effects of anti-human PTHrP antibody on II-6 mRNA expression in ST2 cells. As shown in Figure 7C, this antibody partially inhibited OSCC (BHY, Ca9, HSC3, and
A
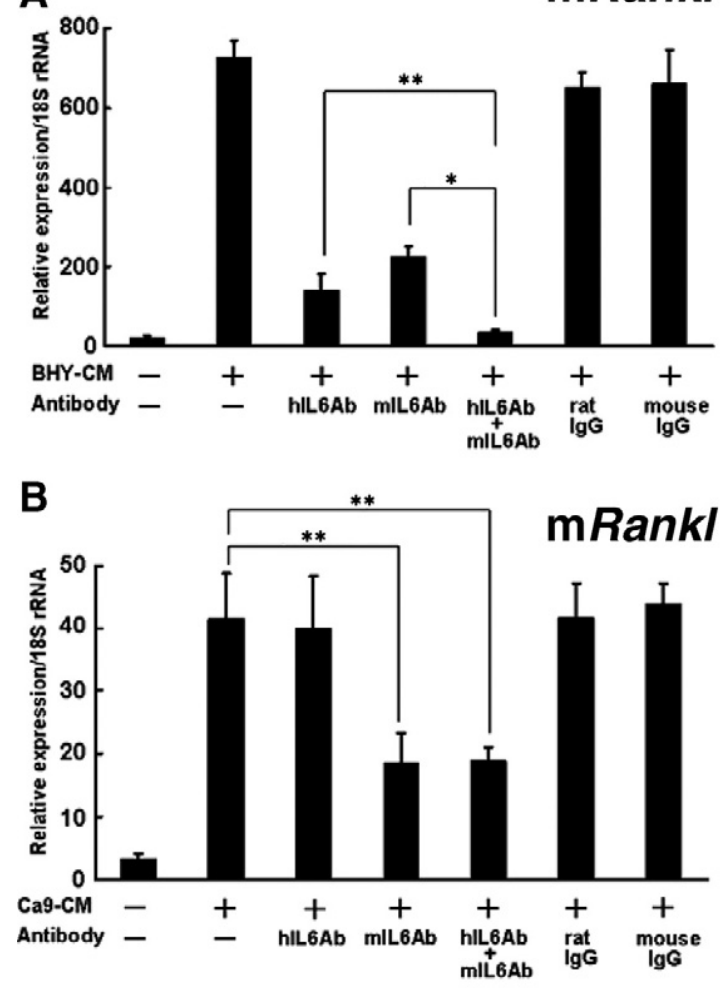

C

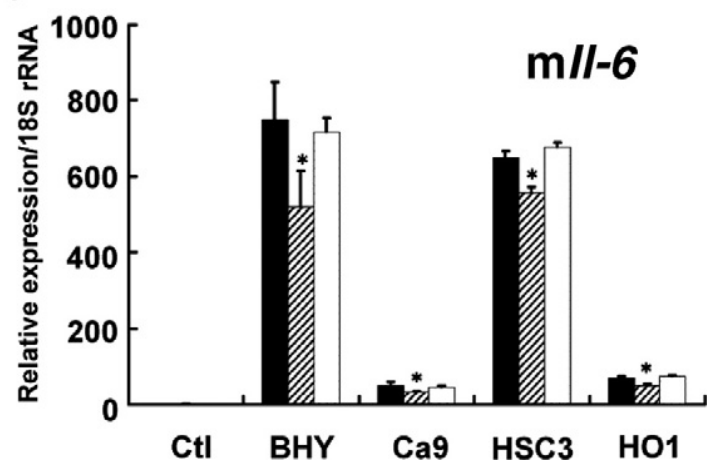

Figure 7. Effects of anti-human IL-6 antibody (hIL6Ab) and anti-mouse IL-6 antibody (mIL6Ab) on Rankl mRNA expression induced by BHY-CM (A) and Ca9-CM (B) in ST2 cells. ST2 cells were cultured for 2 days in the presence or absence of each CM, and the Rankl mRNA expression in ST2 cells was determined by using mouse specific primers. ${ }^{*} P<0.01,{ }^{* *} P<0.05$. C: Effect of anti-human PTHrP antibody on mouse $I l-6$ mRNA expression induced by CM-isolated from OSCC cell lines in ST2 cells. ST2 cells were cultured for 2 days in the presence or absence of CM isolated from each OSCC cell line, and the effect of anti-PTHrP antibody on $I l-6$ expression was determined. In each experiment, the cells were treated with $10 \mu \mathrm{g} / \mathrm{ml}$ each antibody. Black bars, values treated with each CM only; gray bars, values treated with each CM and anti-PTHrP antibody; white bars, values treated with each $\mathrm{CM}$ and normal mouse $\operatorname{IgG}_{1}(10 \mu \mathrm{g} / \mathrm{ml})$. ${ }^{*} P<0.05$, significantly different from each $\mathrm{CM}$ induced $\mathrm{Il}-6 \mathrm{mRNA}$ expression.

HO1)-induced II-6 mRNA expression (15 to 36\% inhibition) at a concentration of $10 \mu \mathrm{g} / \mathrm{ml}$. Almost the same inhibitory effects on BHY-CM-induced II-6 mRNA expression in ST2 cells occurred at concentrations of 5 and 10 $\mu \mathrm{g} / \mathrm{ml}$ of anti-PTHrP antibody (Supplemental Figure S3, see http://ajp.amjpathol.org), suggesting that the concentration of anti-PTHrP antibody used $(10 \mu \mathrm{g} / \mathrm{ml})$ exerted the maximum inhibitory effect. These results support the 

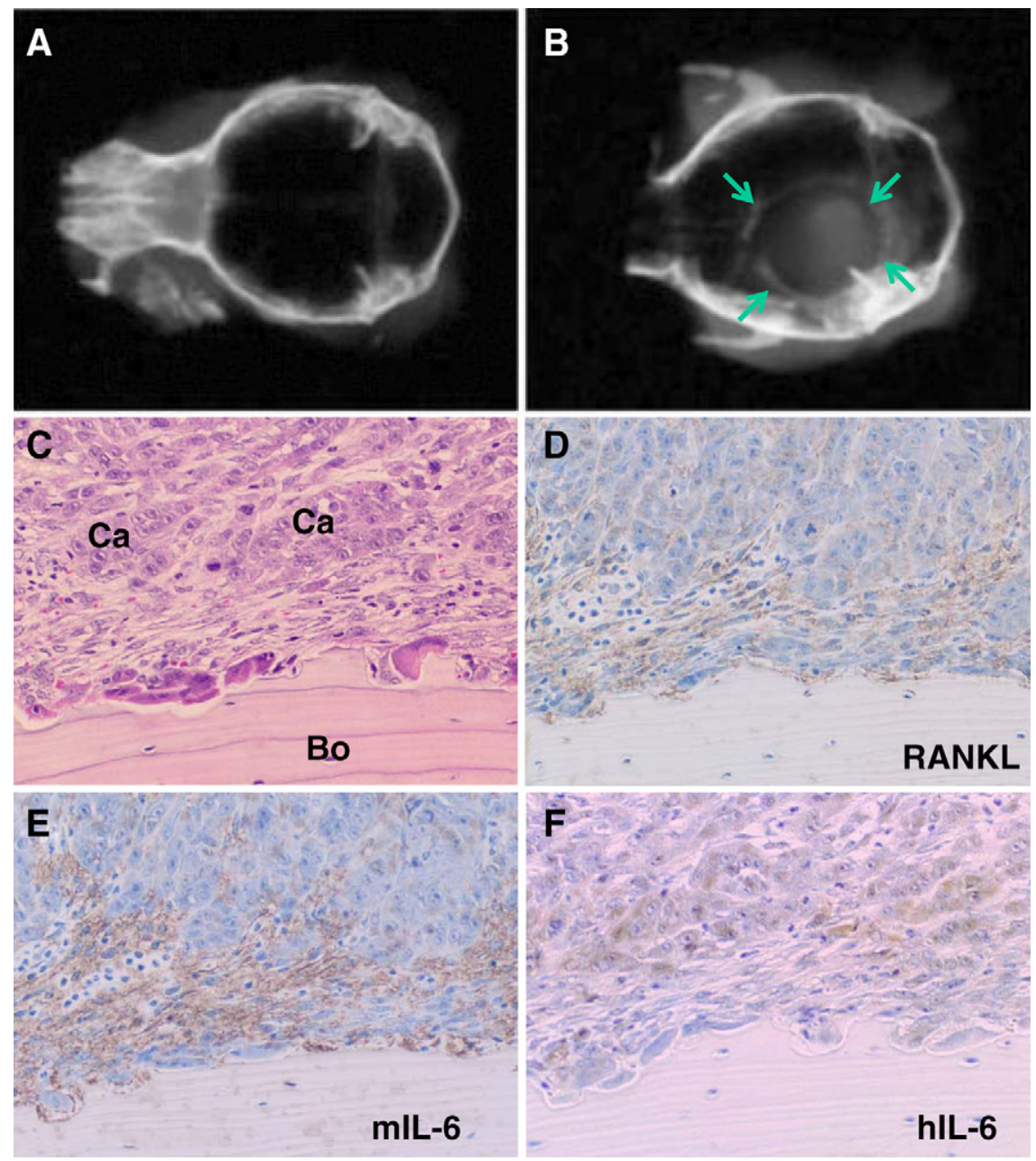

Figure 8. Xenograft experiments of $\mathrm{HSC} 3$ cells into athymic mice. The HSC3 cells were transplanted onto the periosteal region of parietal bone as described in Materials and Methods. $\mathbf{A}$ and B: Bone resorption was confirmed by soft $\mathrm{X}$-ray examination 3 weeks after transplantation. A soft X-ray picture of calvaria in control group with injection of PBS only (A). A soft X-ray picture of calvaria in experimental group with injection of HSC3 cells (B). Arrows in $\mathbf{B}$ indicate the margin of bone destruction. C-F: Histology of bone resorbing region by HSC3 cells in semiserial sections. C: Typical histological ap pearance of the bone resorbing region by HSC3 cells. Note that fibroblastic cells are scattered between cancer cells $(\mathrm{Ca})$ and bone (Bo) surface. Numerous osteoclasts are observed on the bone surface. H\&E stain. D: Immunohistochemical analysis of RANKL. Note the RANKL-positive fibroblastic cells between cancer cells and bone surface. E: Immunohistochemical analysis of mouse IL-6 (mIL-6). Note that only fibroblastic cells between cancer cells and bone surface are positive for mIL-6. F: Immunohistochemical analysis of human IL-6 (hIL-6). Note that only cancer cells are positive for hIL-6.

hypothesis that PTHrP is partially involved in the regulation of cancer-induced IL-6 expression in stromal cells.

\section{Xenograft Experiments of HCS3 Cells into Athymic Mice}

Soft X-ray analysis revealed that transplantation of HSC3 cells onto the periosteal region of the parietal bone induced marked bone destruction in all athymic mice injected with HSC3 cells $(n=3)$ (Figure 8, A and B). Histologically, many osteoclasts were observed on the bone surface exposed to the injected cancer cells (Figure $8 \mathrm{C}$ ). In addition, numerous fibroblastic cells were located between the cancer cells and the resorbing bone surface. These findings are similar to the bone resorption caused by human OSCC found in the surgical specimens. We therefore investigated the expression of RANKL, human IL-6, and mouse IL-6 by immunohistochemistry. The fibroblastic cells between the cancer cells and the bone surface expressed RANKL (Figure 8D). Interestingly, mouse IL-6 was identified in the fibroblastic cells (Figure $8 \mathrm{E}$ ), which originated from athymic mice, whereas the expression of human IL-6 was limited to the cancer cells, which were derived from human OSCC (Figure 8F).

\section{Discussion}

Several reports have demonstrated that the elevated levels of serum IL-6 in patients with head and neck SCC serve as a valuable biomarker for predicting clinical outcome such as radioresistance, recurrence, and survival. ${ }^{16-18}$ However, direct evidence of IL-6 production by OSCC is not well documented. Woods et $\mathrm{a}^{38}$ reported that IL-6 was expressed in all of the 12 OSCC specimens examined, but other groups have reported that the expression levels varied among the OSCCs they tested. ${ }^{17,39}$ The results of microarray analysis in the present study demonstrated that a few OSCC specimens expressed IL-6. Thus, the cells responsible for the elevated serum IL-6 levels noted in human OSCC patients should be investigated further. The immunohistochemical analysis in this study using bone-invasive human gingival SCC specimens revealed that IL-6 was expressed both in cancer cells located at the periphery of the cancer nests and in the fibroblastic cells at the tumorbone interface. Because various cell types produce IL-6, we confirmed the nature of IL-6-producing cells by dual fluorescence immunohistochemistry and found that fibroblastic cells, not B cells or macrophages, are the major cells responsible for IL-6 production. Furthermore, the number of IL-6-positive fibroblastic cells significantly correlated with 
the number of RANKL-positive fibroblastic cells at the tumor-bone interface. We also found that oral cancer cell lines effectively stimulated IL-6 synthesis in cultured stromal cells and that this cytokine participates in the induction of RANKL expression.

Thus, we are the first group to propose that IL-6 synthesized by stromal cells plays a significant role in OSCCinduced osteoclast formation, but the regulatory mechanism by which OSCC cells stimulate IL-6 synthesis in stromal cells remains unclear. We demonstrated that an anti-PTHrP antibody partially inhibited OSCC-CM-induced II-6 expression in ST2 cells. PTHrP is reported to induce IL-6 production in osteoblastic cells ${ }^{37}$; thus, it might be one of the secretions of OSCC that stimulates $\mathrm{IL}-6$ expression in stromal cells. Mata et $\mathrm{al}^{40}$ reported on the synergistic effects of IL-6 and PTHrP on bone resorption, and so PTHrP might enhance IL-6 activity during bone destruction by OSCC. However, other factors involved in induction of IL-6 in stromal cells should be explored because anti-PTHrP antibody exerted only partial inhibitory effects (15 to 36\%) (Figure 7C). Sohara et $\mathrm{al}^{41}$ reported that neuroblastoma cells also stimulate IL-6 production in bone marrow mesenchymal stem cells and that this cytokine subsequently activates osteoclasts. More recently, they demonstrated that galectin-3-binding protein secreted by neuroblastoma cells is responsible for inducing IL-6 expression in bone marrow stromal cells. ${ }^{42}$ It has also been reported that myeloma cells up-regulate IL-6 in bone marrow stromal cells. ${ }^{43,44}$ In the present study, we found that IL-6 expression in stromal cells was enhanced to a greater degree by CM derived from OSCC cells than by those derived from non-oral cancer cells, suggesting that the specific factor(s) produced by OSCC induces IL-6 expression in stromal cells.

We identified IL-6-positive osteoclasts on the resorbing bone surface at the tumor-bone interface by immunohistochemical analysis. Expression of IL-6 in osteoclasts has been reported in several bone diseases, such as Paget's disease of bone, ${ }^{45}$ giant cell tumors, ${ }^{46}$ renal osteodystrophy, ${ }^{47}$ and fibrous dysplasia of bone. ${ }^{48}$ It was suggested that the numbers of IL-6-expressing osteoclasts are significantly higher in osteoclasts within diseased bone than in normal osteoclasts. ${ }^{48}$ Previous reports suggested that IL-6 synthesized by osteoclasts plays a role in osteoclastogenesis via an autocrine/paracrine fashion in pathological bone diseases. ${ }^{46,49,50}$ Thus, IL-6 synthesized by stromal cells, cancer cells, and osteoclasts may collaborate to induce osteoclastic bone resorption in OSCC-associated bone destruction and elevate serum IL-6 levels in patients with OSCC.

In the present study, microarray analyses of human primary OSCC specimens revealed that many of the specimens overexpressed PTHrP mRNA. The PTHrP expression profile identified in this study was consistent with that described in previous reports. ${ }^{26,27}$ By using a neutralizing antibody against PTHrP, we found that PTHrP is involved in Rankl mRNA expression in stromal cells and osteoclast formation induced by $\mathrm{CM}$ derived from oral cancer cells. These results provide the first evidence that PTHrP synthesized by oral cancer cells participates in osteoclast formation. Although these findings suggest that PTHrP is involved

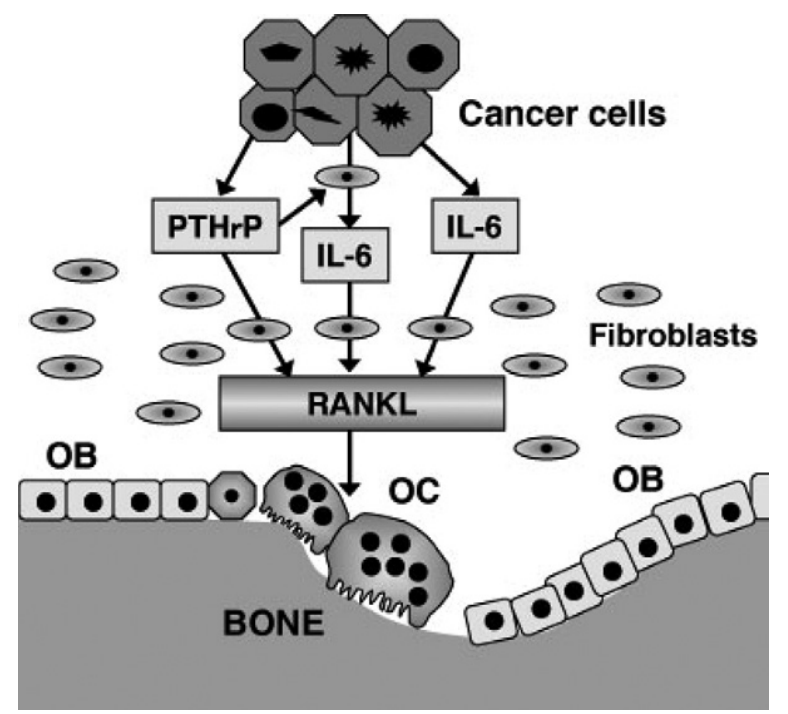

Figure 9. Schematic representation of the roles of IL-6 and PTHrP in OSCC-induced osteoclast formation. OC, osteoclasts; OB, osteoblasts.

in bone resorption induced by OSCC, the contribution of PTHrP to bone destruction might be smaller than that of IL-6 because neutralizing antibody against IL-6 more effectively inhibited Rankl expression in ST2 cells and osteoclast formation than that against PTHrP.

Figure 9 summarizes our hypothesis that IL-6 and PTHrP play important roles in OSCC-induced osteoclast formation. OSCC cells provide a suitable microenvironment for osteoclast formation not only by producing IL-6 and PTHrP but also by stimulating stromal cells to synthesize IL-6. IL-6 and PTHrP produced by OSCC cells and IL-6 by stromal cells induce fibroblastic cells/osteoblasts to synthesize RANKL, and subsequently they activate osteoclast formation and bone resorption. To prove this hypothesis, suitable in vivo experimental models are required. A few animal models have been generated for this purpose in previous studies $^{13,14}$; however, in these models, OSCC cells are usually in direct contact with the resorbing bone surface lacking the substantial amount of fibrous stroma typically observed in the case of bone-invasive human OSCC. Therefore, these models will not be of much help in clarifying the role of IL-6 synthesized by stromal cells in response to OSCC. To overcome this problem, we successfully developed a suitable bone destruction model by xenotransplantation of OSCC cells (HSC3) into the periosteal region of athymic mice, which exhibits bone invasion patterns similar to those of human OSCC. In this model, we confirmed RANKL expression in fibroblastic cells at the tumor-bone interface. IL-6 expression was also identified in both fibroblastic and cancer cells. Thus, this model will be useful in understanding molecular mechanisms underlying cancer-associated bone destruction.

\section{Acknowledgments}

We thank Dr. Yukio Kato for providing the human mesenchymal stem cells and Dr. Masato Okamoto for providing $\mathrm{BHY}$ cells. 


\section{References}

1. Semba I, Matsuuchi H, Miura Y: Histomorphometric analysis of osteoclastic resorption in bone directly invaded by gingival squamous cell carcinoma. J Oral Pathol Med 1996, 25:429-435

2. Wong RJ, Keel SB, Glynn RJ, Varvares MA: Histological pattern of mandibular invasion by oral squamous cell carcinoma. Laryngoscope 2000, 110:65-72

3. Brown JS, Lowe D, Kalavrezos N, D'Souza J, Magennis P, Woolgar J: Patterns of invasion and routes of tumor entry into the mandible by oral squamous cell carcinoma. Head Neck 2002, 24:370-383

4. Shaw RJ, Brown JS, Woolgar JA, Lowe D, Rogers SN, Vaughan ED: The influence of the pattern of mandibular invasion on recurrence and survival in oral squamous cell carcinoma. Head Neck 2004, 26:861-869

5. Takayanagi $\mathrm{H}$ : Osteoimmunology: shared mechanisms and crosstalk between the immune and bone systems. Nat Rev Immunol 2007 7:292-304

6. Boyce BF, Xing L: Functions of RANKL/RANK/OPG in bone modeling and remodeling. Arch Biochem Biophys 2008, 473:139-146

7. Thomas GP, Baker SU, Eisman JA, Gardiner EM: Changing RANKL/ OPG mRNA expression in differentiating murine primary osteoblasts. J Endocrinol 2001, 170:451-460

8. Lacey DL, Timms E, Tan HL, Kelley MJ, Dunstan CR, Burgess T, Elliott R, Colombero A, Elliott G, Scully S, Hsu H, Sullivan J, Hawkins N, Davy E, Capparelli C, Eli A, Qian YX, Kaufman S, Sarosi I, Shalhoub V, Senaldi G, Guo J, Delaney J, Boyle WJ: Osteoprotegerin ligand is a cytokine that regulates osteoclast differentiation and activation. Cell 1998, 93:165-176

9. Yasuda H, Shima N, Nakagawa N, Yamaguchi K, Kinosaki M, Mochizuki S, Tomoyasu A, Yano K, Goto M, Murakami A, Tsuda E, Morinaga T, Higashio K, Udagawa N, Takahashi N, Suda T: Osteoclast differentiation factor is a ligand for osteoprotegerin/osteoclastogenesisinhibitory factor and is identical to TRANCE/RANKL. Proc Natl Acad Sci USA 1998, 95:3597-3602

10. Simonet WS, Lacey DL, Dunstan CR, Kelley M, Chang MS, Luthy R, Nguyen HQ, Wooden S, Bennett L, Boone T, Shimamoto G, DeRose M, Elliott R, Colombero A, Tan HL, Trail G, Sullivan J, Davy E, Bucay N, Renshaw-Gegg L, Hughes TM, Hill D, Pattison W, Campbell P, Sander S, Van G, Tarpley J, Derby P, Lee R, Boyle WJ: Osteoprotegerin: a novel secreted protein involved in the regulation of bone density. Cell 1997, 89:309-319

11. Okamoto M, Hiura K, Ohe G, Ohba Y, Terai K, Oshikawa T, Furuichi S, Nishikawa H, Moriyama K, Yoshida H, Sato M: Mechanism for bone invasion of oral cancer cells mediated by interleukin- 6 in vitro and in vivo. Cancer 2000, 89:1966-1975

12. Tada T, Jimi E, Okamoto M, Ozeki S, Okabe K: Oral squamous cell carcinoma cells induce osteoclast differentiation by suppression of osteoprotegerin expression in osteoblasts. Int J Cancer 2005, 116:253-262

13. Shibahara T, Nomura $\mathrm{T}$, Cui NH, Noma H: A study of osteoclastrelated cytokines in mandibular invasion by squamous cell carcinoma. Int J Oral Maxillofac Surg 2005, 34:789-793

14. Cui N, Nomura T, Noma H, Yokoo K, Takagi R, Hashimoto S, Okamoto M, Sato M, Yu G, Guo C, Shibahala T: Effect of YM529 on a model of mandibular invasion by oral squamous cell carcinoma in mice. Clin Cancer Res 2005, 11:2713-2719

15. O'Brien CA, Gubrij I, Lin SC, Saylors RL, Manolagas SC: STAT3 activation in stromal/osteoblastic cells is required for induction of the receptor activator of $\mathrm{NF}-\kappa \mathrm{B}$ ligand and stimulation of osteoclastogenesis by gp130-utilizing cytokines or interleukin-1 but not 1,25-dihydroxyvitamin $\mathrm{D}_{3}$ or parathyroid hormone. J Biol Chem 1999, 274:19301-19308

16. Jablonska E, Piotrowski L, Grabowska Z: Serum levels of IL-1 $\beta$, IL-6, TNF- $\alpha$, sTNF-RI and CRP in patients with oral cavity cancer. Pathol Oncol Res 1997, 3:126-129

17. Chen Z, Malhotra PS, Thomas GR, Ondrey FG, Duffey DC, Smith CW, Enamorado I, Yeh NT, Kroog GS, Rudy S, McCullagh L, Mousa S, Quezado M, Herscher LL, Van Waes C: Expression of proinflammatory and proangiogenic cytokines in patients with head and neck cancer. Clin Cancer Res 1999, 5:1369-1379

18. Duffy SA, Taylor JM, Terrell JE, Islam M, Li Y, Fowler KE, Wolf GT, Teknos TN: Interleukin-6 predicts recurrence and survival among head and neck cancer patients. Cancer 2008, 113:750-757

19. Burtis WJ, Wu T, Bunch C, Wysolmerski JJ, Insogna KL, Weir EC, Broadus AE, Stewart AF: Identification of a novel 17,000-dalton parathyroid hormone-like adenylate cyclase-stimulating protein from a tumor associated with humoral hypercalcemia of malignancy. J Biol Chem 1987, 262:7151-7156

20. Strewler GJ, Stern PH, Jacobs JW, Eveloff J, Klein RF, Leung SC, Rosenblatt M, Nissenson RA: Parathyroid hormonelike protein from human renal carcinoma cells. Structural and functional homology with parathyroid hormone, J Clin Invest 1987, 80:1803-1807

21. Moseley JM, Kubota M, Diefenbach-Jagger H, Wettenhall RE, Kemp BE, Suva LJ, Rodda CP, Ebeling PR, Hudson PJ, Zajac JD, Martin TJ: Parathyroid hormone-related protein purified from a human lung cancer cell line. Proc Natl Acad Sci USA 1987, 84:5048-5052

22. Shulkes A, Fletcher DR, Rubinstein C, Ebeling PR, Martin TJ: Production of calcitonin gene related peptide, calcitonin and $\mathrm{PTH}$-related protein by a prostatic adenocarcinoma. Clin Endocrinol (Oxf) 1991, 34:387-393

23. Malakouti S, Asadi FK, Kukreja SC, Abcarian HA, Cintron JR: Parathyroid hormone-related protein expression in the human colon: immunohistochemical evaluation. Am Surg 1996, 62:540-544; discussion 544-545

24. Dunne FP, Bowden SJ, Brown JS, Ratcliffe WA, Browne RM: Parathyroid hormone related protein in oral squamous cell carcinomas invading the mandible. J Clin Pathol 1995, 48:300-303

25. Tsuchimochi M, Kameta A, Sue M, Katagiri M: Immunohistochemical localization of parathyroid hormone-related protein (PTHrP) and serum PTHrP in normocalcemic patients with oral squamous cell carcinoma. Odontology 2005, 93:61-71

26. Kornberg LJ, Villaret D, Popp M, Lui L, McLaren R, Brown H, Cohen D, Yun J, McFadden M: Gene expression profiling in squamous cell carcinoma of the oral cavity shows abnormalities in several signaling pathways. Laryngoscope 2005, 115:690-698

27. Deyama Y, Tei K, Yoshimura Y, Izumiyama Y, Takeyama S, Hatta M, Totsuka Y, Suzuki K: Oral squamous cell carcinomas stimulate osteoclast differentiation. Oncol Rep 2008, 20:663-668

28. Roodman GD: Biology of osteoclast activation in cancer. J Clin Oncol 2001, 19:3562-3571

29. Karnoub AE, Dash AB, Vo AP, Sullivan A, Brooks MW, Bell GW, Richardson AL, Polyak K, Tubo R, Weinberg RA: Mesenchymal stem cells within tumour stroma promote breast cancer metastasis. Nature 2007, 449:557-563

30. Mishra PJ, Mishra PJ, Glod JW, Banerjee D: Mesenchymal stem cells: flip side of the coin. Cancer Res 2009, 69:1255-1258

31. Ishikuro M, Sakamoto K, Kayamori K, Akashi T, Kanda H, Izumo T, Yamaguchi A: Significance of the fibrous stroma in bone invasion by human gingival squamous cell carcinomas. Bone 2008, 43:621-627

32. Takagi N, Mihara M, Moriya Y, Nishimoto N, Yoshizaki K, Kishimoto T, Takeda Y, Onsugi Y: Blockage of interleukin-6 receptor ameliorates joint disease in murine collagen-induced arthritis. Arthritis Rheum 1998, 41:2117-2121

33. Onuma E. Sato K, Saito H, Tsunenari T, Ishii K, Esaki K, Yabuta N Wakahara Y, Yamada-Okabe H, Ogata E: Generation of a humanized monoclonal antibody against human parathyroid hormone-related protein and its efficacy against humoral hypercalcemia of malignancy. Anticancer Res 2004, 24:2665-2673

34. Nguyen ST, Hasegawa S, Tsuda H, Tomioka H, Ushijima M, Noda M, Omura K, Miki Y: Identification of a predictive gene expression signature of cervical lymph node metastasis in oral squamous cell carcinoma. Cancer Sci 2007, 98:740-746

35. Tsutsumi S, Shimazu A, Miyazaki K, Pan H, Koike C, Yoshida E, Takagishi K, Kato Y: Retention of multilineage differentiation potential of mesenchymal cells during proliferation in response to FGF. Biochem Biophys Res Commun 2001, 288:413-419

36. Kondo T, Kitazawa R, Yamaguchi A, Kitazawa S: Dexamethasone promotes osteoclastogenesis by inhibiting osteoprotegerin through multiple levels. J Cell Biochem 2008, 103:335-345

37. Guillén C, Martinez P, de Gortazar AR, Martinez ME, Esbrit P: Both Nand $\mathrm{C}$-terminal domains of parathyroid hormone-related protein increase interleukin- 6 by nuclear factor-kappa B activation in osteoblastic cells. J Biol Chem 2002, 277:28109-28117

38. Woods KV, El-Naggar A, Clayman GL, Grimm EA: Variable expression of cytokines in human head and neck squamous cell carcinoma cell lines and consistent expression in surgical specimens. Cancer Res 1998, 58:3132-3141

39. Wang YF, Chang SY, Tai SK, Li WY, Wang LS: Clinical significance of interleukin-6 and interleukin-6 receptor expressions in oral squamous cell carcinoma. Head Neck 2002, 24:850-858 
40. de la Mata J, Uy HL, Guise TA, Story B, Boyce BF, Mundy GR, Roodman GD: Interleukin- 6 enhances hypercalcemia and bone resorption mediated by parathyroid hormone-related protein in vivo. J Clin Invest 1995, 95:2846-2852

41. Sohara $Y$, Shimada H, Minkin C, Erdreich-Epstein A, Nolta JA, DeClerck YA: Bone marrow mesenchymal stem cells provide an alternate pathway of osteoclast activation and bone destruction by cancer cells. Cancer Res 2005, 65:1129-1135

42. Fukaya $Y$, Shimada H, Wang LC, Zandi E, DeClerck YA: Identification of galectin-3-binding protein as a factor secreted by tumor cells that stimulates interleukin-6 expression in the bone marrow stroma. J Biol Chem 2008, 283:18573-18581

43. Gunn WG, Conley A, Deininger L, Olson SD, Prockop DJ, Gregory CA: A crosstalk between myeloma cells and marrow stromal cells stimulates production of DKK1 and interleukin-6: a potential role in the development of lytic bone disease and tumor progression in multiple myeloma. Stem Cells 2006, 24:986-991

44. Arnulf B, Lecourt S, Soulier J, Ternaux B, Lacassagne MN, Crinquette A, Dessoly J, Sciaini AK, Benbunan M, Chomienne C, Fermand JP, Marolleau JP, Larghero J: Phenotypic and functional characterization of bone marrow mesenchymal stem cells derived from patients with multiple myeloma. Leukemia 2007, 21:158-163

45. Roodman GD, Kurihara N, Ohsaki Y, Kukita A, Hosking D, Demulder A, Smith JF, Singer FR: Interleukin 6. A potential autocrine/paracrine factor in Paget's disease of bone, J Clin Invest 1992, 89:46-52

46. Reddy SV, Takahashi S, Dallas M, Williams RE, Neckers L, Roodman GD: Interleukin-6 antisense deoxyoligonucleotides inhibit bone resorption by giant cells from human giant cell tumors of bone. J Bone Miner Res 1994, 9:753-757

47. Langub MC Jr, Koszewski NJ, Turner HV, Monier-Faugere MC, Geng Z, Malluche HH: Bone resorption and mRNA expression of IL-6 and IL-6 receptor in patients with renal osteodystrophy. Kidney Int 1996, 50:515-520

48. Riminucci M, Kuznetsov SA, Cherman N, Corsi A, Bianco P, Gehron Robey P: Osteoclastogenesis in fibrous dysplasia of bone: in situ and in vitro analysis of IL-6 expression. Bone 2003, 33:434-442

49. Roodman GD: Regulation of osteoclast differentiation. Ann NY Acad Sci 2006, 1068:100-109

50. O'Keefe RA, Teot LA, Singh D, Puzas JE, Rosier RN, Hicks DG: Osteoclasts constitutively express regulators of bone resorption: an immunohistochemical and in situ hybridization study. Lab Invest 1997, 76:457-465 